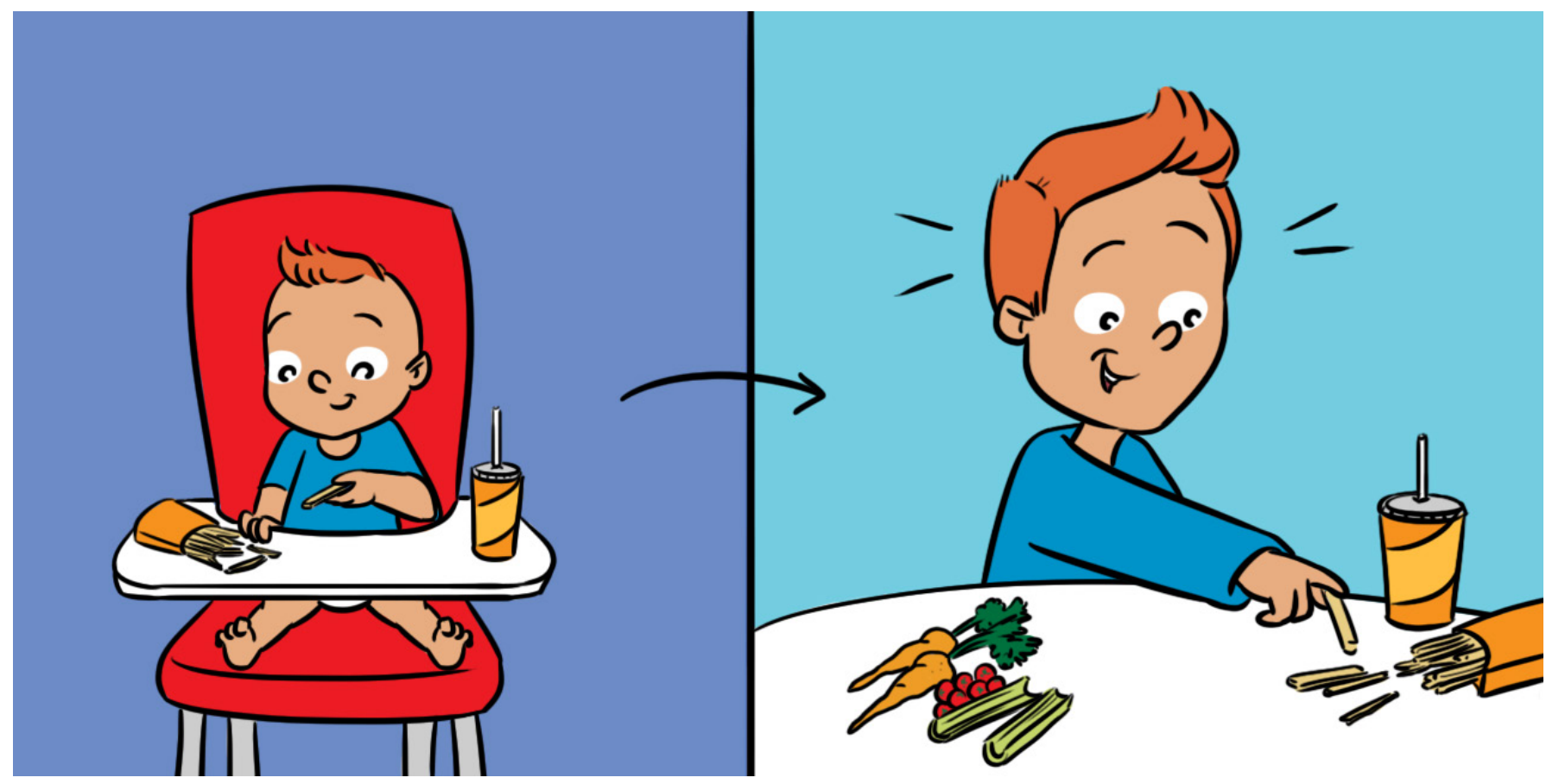

\title{
HOW FOOD CAN CHANGE A BABY'S BRAIN
}

\section{Luba Sominsky and Sarah J. Spencer*}

School of Health and Biomedical Sciences, RMIT University, Melbourne, VIC, Australia

\section{YOUNG REVIEWER:}

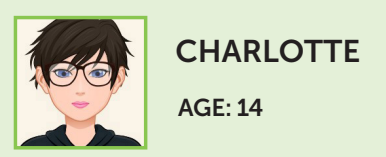

Which snack would you prefer? A bag of chips or carrot sticks? Ice cream or an apple? Most of us would probably choose the junk food. While sometimes it is OK to have chips or ice cream, if you eat junk food all the time it is pretty obvious you will begin to gain weight. What might not be obvious is that a poor diet can also change your brain! Even before a baby is born, what the parents eat can affect how the baby's brain develops. Here, we tested what happens to the brain if we begin to eat healthier as we grow, after eating poorly early on in life. We found that eating poorly when the brain is developing changes our decisions about food. However, we can fix some of this damage with a good diet. Excellent news for kids and adults who have health problems from eating a poor diet early in life.

\section{A BABY'S DIET CAN CHANGE HOW IT THINKS ABOUT FOOD}

Scientists now know our diet in early life is really important for our health in the long-term. If your dad was obese when you were conceived, or if your mom ate too much junk food when she was pregnant with you, 
HORMONE ("HORMOAN')

A substance coming from one of the organs in the body that travels to another organ and tells it what to do.

\section{GHRELIN ( "GRE-}

LIN")

A hormone that tells the brain to eat more.

HYPOTHALAMUS ( "HIE-PO-THAL-AMUS")

A brain region that is responsible for controlling feeding (and some other important things).

\section{LEPTIN ( "LEP-TIN")}

A hormone that tells the brain to stop eating.

\section{NEURON ("NEW-}

RON')

A cell in the brain that receives information from the body or other neurons and passes the information on. Lots of neurons together control how we respond to the information and what we think or feel about it. or if you started eating fries and drinking cola before you could walk, these bad eating habits can play havoc with your brain and the way you think about food. We were interested to see if the negative effects of eating poorly in early life could be reversed by eating a healthier diet as we get older.

\section{HOW DO WE KNOW WHEN WE ARE HUNGRY?}

As both children and adults, we have brains that are usually very good at telling us when we are hungry and when we are full. You may notice that, just before dinner time, you start feeling hungry, even if you are busy playing an interesting game. But you do not usually feel hungry all day. This is because we have a hormone called "ghrelin" that increases in the blood just before meal times or when we have not eaten for a while.

Ghrelin comes from the stomach and travels in the blood. Ghrelin ends up in the brain and tells the brain to feel hungry and start eating. Just like the players on a football team, all of the different parts of the brain have different jobs to do. They keep communicating with each other to help each other out, but they still have fairly separate functions. The part of the brain that ghrelin talks with to tell our bodies that we are hungry is called the hypothalamus. The hypothalamus is really important. Different parts of the hypothalamus control how stressed we feel, whether we are able to have babies when we grow up, how thirsty we are, how we grow, and also...how hungry we feel [1].

Another important hormone that tells kids and adults how hungry they feel is leptin. Leptin comes out of the fat in the body and tells us to stop feeling hungry. Leptin is usually present all the time and, like a red traffic light, it stops us from being desperately hungry throughout the whole day. But, if we get so starving that our fat levels decrease, no more leptin is made, and we start feeling really hungry once more. Together, ghrelin and leptin talk to the hypothalamus to make sure that we eat enough to keep our energy levels high and our bodies healthy.

\section{HOW DOES OUR HUNGER-SENSE DEVELOP?}

Back to babies, though. Babies that are still inside their moms do not have to eat to get their energy. They get their nutrition and energy from mom. So, when the baby is developing, ghrelin and leptin do a different job. They help the baby's brain to develop. Ghrelin and leptin are especially important in unborn babies for making neurons grow between different parts of the hypothalamus [2, 3]. 
Figure 1

(A) A diagram of a normal neuron. The cell body receives information from the external world (such as from light if it is a neuron in your eye) or from other neurons. The axon carries the information from the cell body to the synapses. It is then passed on to other neurons or to organs of the body, like the stomach, at the synapses. (B) A microscope image of neurons in the hypothalamus of a rat. The large image shows lots of cell bodies in yellow (the roundish blobs). The speckly coloring is the axons. Each cell body is about $10 \mu \mathrm{m}$ in diameter
Neurons are tiny cells in the brain and they control how different parts of the brain talk to each other and how we get information from our eyes, and ears, and stomachs, to the brain. Most neurons look a bit like wires with a blob on one end (see Figure 1 for a picture of some real neurons and some diagrams of what neurons look like). Information is received at the blob end, travels down the wire (axon), splits, and is delivered to the other neurons at distant parts of the brain.

Fun fact: Most neuron wires (axons) are so thin that 1,000 of them can fit in $1 \mathrm{~mm}$. The squid has a giant neuron that is so big we can see it without a microscope. Its axon can be $1 \mathrm{~mm}$ wide, the size of a small pencil lead!

In babies that have not been born yet, the neurons that send information about food and hunger (let us call these "feeding neurons") have not got the really long axons yet, so they cannot talk very well to other bits of the brain. Leptin helps these axons grow. Ghrelin stops them from growing too much. If babies do not have enough leptin at this time, these feeding neurons cannot grow and then can never carry information about how hungry or full the body feels. If there is not enough ghrelin, these feeding neurons grow too much (see Figure 1 for how this might look in the brain). In both cases, the baby can grow

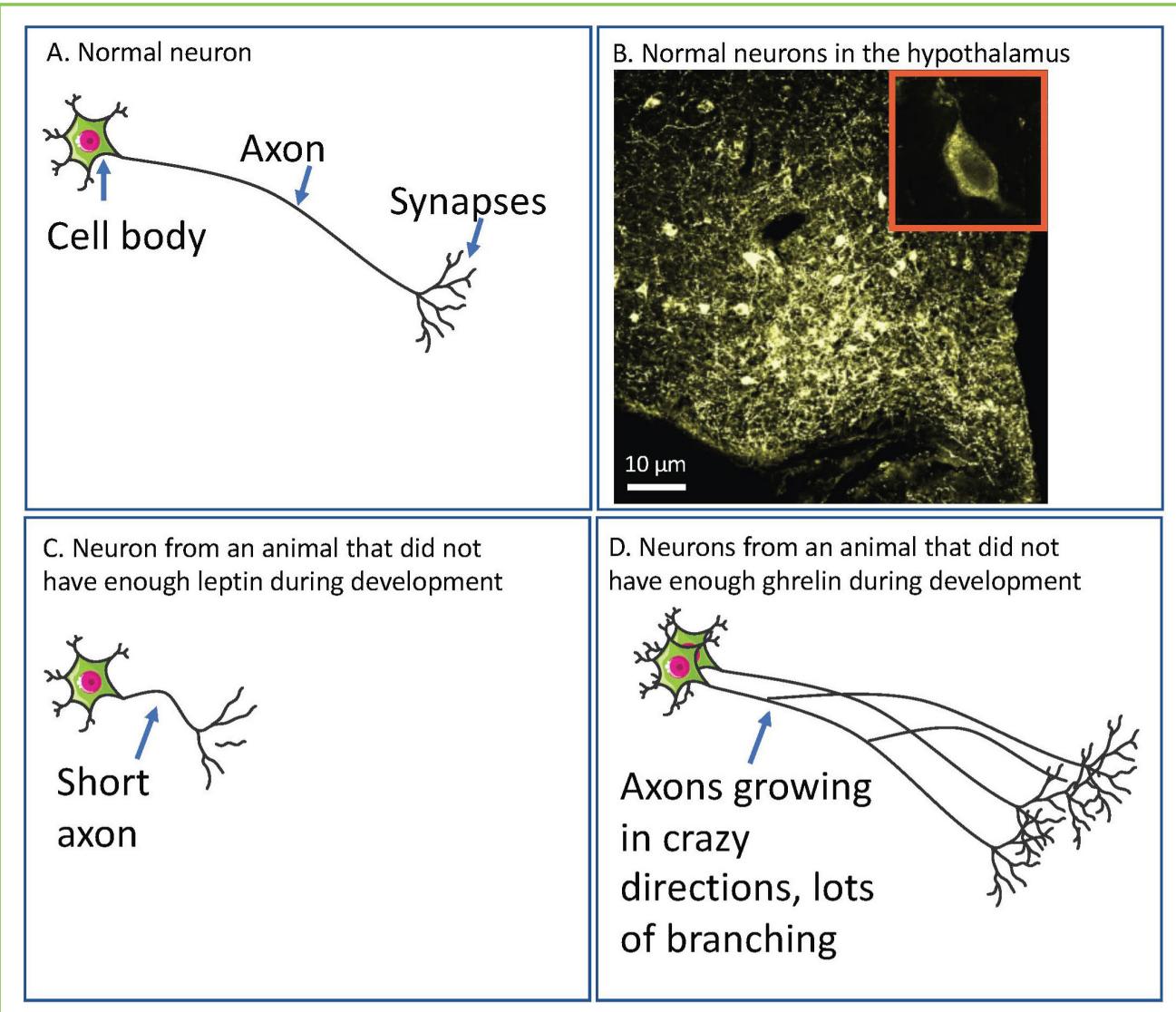

Figure 1 
Figure 1

\section{Continued}

(one $\mathrm{mm}$ divided into 100 pieces). The small inset shows a zoomed in view of one cell body. The darker oval in the center is the nucleus, which contains all the information the neuron uses to communicate. (C) If neurons in the hypothalamus do not have enough leptin, then their axons do not grow properly. This means these axons cannot properly carry information about how full or hungry the body is. (D) If neurons in the hypothalamus do not have enough ghrelin, then they do not stop growing when they should. This means these axons might carry so many signals that the message is confused and the brain still cannot communicate effectively about how full or hungry the body is. up unable to tell properly if it is hungry or full. The usual result of this for the kid growing up is that he or she eats too much.

\section{WHAT MOM EATS CAN CHANGE HOW THE BABY'S BRAIN DEVELOPS}

Scientists now know that what mom eats during pregnancy, and whether she is obese, may change the amount of leptin and ghrelin in the baby. The levels of leptin and ghrelin may change the way the baby's feeding neurons grow and how the baby senses hunger when it grows up. Scientists in the past have suggested that this effect is permanent. They found that once babies are past the right time for the hypothalamus to develop there is nothing that can be done to get these feeding neurons to grow properly [4]. BUT...these experiments were done in animals that could not make leptin at all. We were interested to know if these changes to the way the neurons grow could actually be reversed in normal individuals, by a balanced diet starting after the baby is born.

\section{USING RATS AND MICE TO FIGURE OUT WHAT IS GOING ON IN THE HUMAN BRAIN}

For most scientific studies, it is pretty hard to look inside a human brain to find out what is going on. So, we use what are called animal models, usually rats and mice. Rats may seem very different from humans, but they are actually quite similar. Rats see and smell and walk and sleep, they get tired and scared. They also get hungry, eat, and feel full. The way rats know they are hungry is because of ghrelin and leptin talking to the same part of the brain as they do in humans, the hypothalamus.

There is one key difference between humans and rats, though. In humans, the feeding neurons start growing before the baby is born. In rats, these feeding neurons start growing after birth. In our laboratory, we can use this key difference to test how diet affects ghrelin, leptin, and feeding neuron growth without affecting the mom's pregnancy or any other factors.

In our experiment, we took two groups of mother rats that had just given birth and we changed the number of babies each mother had to feed. Rat mothers usually give birth to around 12 babies (ask your mom how she would like to have 12 kids all at once!). So, feeding 12 babies is normal for a rat mother. Because it is the normal state, having 12 babies to feed is called a control group. We compared babies fed in lots of 12 (our control group) with babies fed in lots of only four. When there are only four rat babies, they do not have to fight for their food, so they get 
to eat ALL the time. Because of this they get very fat. After 3 weeks of constant eating, the babies fed in lots of four weighed nearly one-third more than the control group babies. That is one big rat!

\section{WHAT HAPPENS TO LEPTIN AND GHRELIN WHEN BABIES EAT TOO MUCH?}

Because these fat rats drank so much more milk and had so much more fat, they had heaps of leptin. Fourteen times as much leptin compared with rats in the control group! Imagine if you usually need only one cup of milk per day to keep healthy. The amount of milk the rats in our experiment drank would be like you having nearly $2 \mathrm{~L}$ of milk instead! These fat rats also had much less ghrelin-probably because their bodies were trying to tell them they were not hungry.

\section{WHAT HAPPENS TO THE HYPOTHALAMUS WHEN BABIES EAT TOO MUCH?}

Probably because of all this extra leptin, these fat rats had much more feeding neuron growth in the hypothalamus. Even though there were more feeding neurons in the hypothalamus, these feeding neurons did not work as hard. If we gave the fat rats leptin, the leptin failed to talk to the feeding neurons, meaning that the leptin was less able to tell the brain "enough food, stop eating," and so the rat would eat more. It is not surprising, then, that these fat rats cannot properly tell when they are hungry or full, and that they stay fat as they grow up. Or is it...?

\section{POOR DIET IN BABIES CAN DAMAGE THE HYPOTHALAMUS, BUT THIS CAN RECOVER AS THEY GROW UP}

When the rats were done feeding from their mothers' milk and it was time for them to eat solid food, we gave all the rats, the fat ones and the thin ones, a healthy rat food. This food is a wee bit boring...it looks a bit like cardboard, and we are sure they would prefer a burger now and then, but it is very healthy for the rats and contains all the ingredients they need.

After these rats had all been fed this healthy diet for a really long time - until they were grown up, we looked at their brains. Here, we found something really exciting. The feeding neurons had become normal! The feeding neurons were the same in the hypothalamus of the fat rats as they were in the control group! The grown-up fat rats were also able to respond to leptin in the same way that the thin, control rats did. 
The other really interesting thing we found is that the hypothalamus of female rats comes back to normal much more easily than the hypothalamus of male rats [5]. We do not know why this is, yet.

It is still not $100 \%$ good news for rats that had a poor diet when their brains were still developing. We also saw that the fat rats were sicker when they got an infection. The fat rats were also not as good at some memory tests. And, they stay fat even on the healthy diet. But the good news is that, even though poor diet during development can mess up the way feeding neurons grow in the hypothalamus, the brain can recover from this! Our findings are exciting and encouraging for kids and adults who have health problems due to eating a poor diet in the past. Our work suggests that switching to a healthy diet can reverse some of the brain damage caused by a poor diet.

\section{ORIGINAL SOURCE ARTICLE}

Sominsky, L., Ziko, I., Nguyen, T. X., Quach, J., and Spencer, S. J. 2017. Hypothalamic effects of neonatal diet: Reversible and only partially leptin dependent. J. Endocrinol. 234:41-56. doi: 10.1530/JOE-16-0631

\section{REFERENCES}

1. Saper, C. B., Lowell, B. B. 2014. The hypothalamus. Curr. Biol. 24:R1111-6. doi: 10.1016/j.cub.2014.10.023

2. Steculorum, S. M., Collden, G., Coupe, B., Croizier, S., Lockie, S., Andrews, Z. B., et al. 2015. Neonatal ghrelin programs development of hypothalamic feeding circuits. J. Clin. Invest. 125:846-58. doi: 10.1172/JCI73688

3. Bouret, S. G., Draper, S. J., Simerly, R. B. 2004. Formation of projection pathways from the arcuate nucleus of the hypothalamus to hypothalamic regions implicated in the neural control of feeding behavior in mice. J. Neurosci. 24:2797-805. doi: 10.1523/JNEUROSCI.5369-03.2004

4. Bouret, S. G., Draper, S. J., Simerly, R. B. 2004. Trophic action of leptin on hypothalamic neurons that regulate feeding. Science 304:108-10. doi: 10.1126/science.1095004

5. Ziko, I., Sominsky, L., Nguyen, T.-X., Yam, K.-Y., De Luca, S., Korosi, A., et al. 2017. Hyperleptinemia in neonatally overfed female rats does not dysregulate feeding circuitry. Front. Endocrinol. 8:287. doi: 10.3389/fendo.2017.00287

SUBMITTED: 28 May 2018; ACCEPTED: 13 September 2018;

PUBLISHED ONLINE: 09 October 2018.

EDITED BY: Daniel F. Hermens, University of the Sunshine Coast, Australia 


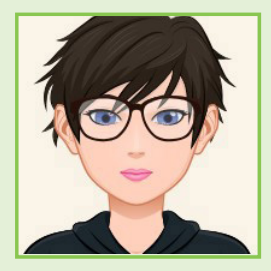

CITATION: Sominsky L and Spencer SJ (2018) How Food Can Change a Baby's Brain. Front. Young Minds 6:53. doi: 10.3389/frym.2018.00053

CONFLICT OF INTEREST STATEMENT: The authors declare that the research was conducted in the absence of any commercial or financial relationships that could be construed as a potential conflict of interest.

COPYRIGHT @ 2018 Sominsky and Spencer. This is an open-access article distributed under the terms of the Creative Commons Attribution License (CC BY). The use, distribution or reproduction in other forums is permitted, provided the original author(s) and the copyright owner(s) are credited and that the original publication in this journal is cited, in accordance with accepted academic practice. No use, distribution or reproduction is permitted which does not comply with these terms.

\section{YOUNG REVIEWER}

\section{CHARLOTTE, AGE: 14}

I am a 14 year old who loves to play games! I can play piano to some extent and clarinet, and I love to eat fruit!

\section{AUTHORS}

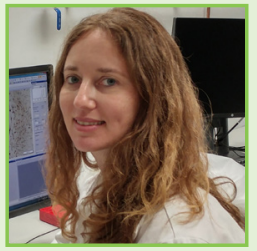

\section{LUBA SOMINSKY}

My research looks at how what happens to us as babies affects our health as adults, including the health of the brain and other important organs. I am also interested in how our bodies are affected by stress, both as babies and as adults. Outside of work, I love traveling around the world and around Australia, where I currently live.

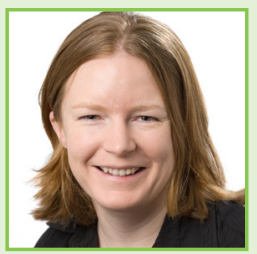

\section{SARAH J. SPENCER}

I am an Associate Professor and researcher at RMIT University in Melbourne, Australia. I study how the brain's immune system responds to different challenges, like stress and diet. I have worked as a scientist in New Zealand, Canada, and Australia and I love how being a scientist gives me opportunities to travel and meet lots of inspiring people. I have two wonderful children who keep me busy at home. *sarah.spencer@rmit.edu.au 